Louisiana State University

LSU Digital Commons

Faculty Publications

School of Animal Sciences

$1-1-1981$

\title{
Ultrastructure of a Feline Extraskeletal Giant Cell Tumor (Malignant Fibrous Histiocytoma)
}

\author{
A. W. Confer \\ School of Veterinary Medicine \\ F. M. Enright \\ School of Veterinary Medicine \\ G. B. Beard \\ School of Veterinary Medicine
}

Follow this and additional works at: https://digitalcommons.Isu.edu/animalsciences_pubs

\footnotetext{
Recommended Citation

Confer, A., Enright, F., \& Beard, G. (1981). Ultrastructure of a Feline Extraskeletal Giant Cell Tumor (Malignant Fibrous Histiocytoma). Veterinary Pathology, 18 (6), 738-744. https://doi.org/10.1177/ 030098588101800604
}

This Article is brought to you for free and open access by the School of Animal Sciences at LSU Digital Commons. It has been accepted for inclusion in Faculty Publications by an authorized administrator of LSU Digital Commons.

For more information, please contact ir@lsu.edu. 


\title{
Ultrastructure of a Feline Extraskeletal Giant Cell Tumor (Malignant Fibrous Histiocytoma)
}

\author{
A. W. Confer, F. M. Enright and G. B. Beard
}

Department of Veterinary Pathology, School of Veterinary Medicine, Louisiana State University, and Goodwood Animal Hospital, Baton Rouge, La.

\begin{abstract}
A subcutaneous extraskeletal giant cell tumor (malignant fibrous histiocytoma) was excised repeatedly from a 9-year-old Domestic Shorthair cat. Ultrastructurally, the mass was composed of fibroblast-like, histiocyte-like, and multinucleated giant cells, and some undifferentiated cells and mononuclear cells intermediate between the fibroblast-like and histiocyte-like cells. Fibroblast-like cells were characterized by abundant well-developed rough endoplasmic reticulum, relatively smooth cytoplasmic membranes, few lysosomal structures, and finely granular chromatin. Histiocyte-like cells resembled immature macrophages. The cell membranes had many villous projections. Rough endoplasmic reticulum varied in quantity. Lysosomes were numerous. Multinucleated giant cells had characteristics of both the fibroblast-like and histiocyte-like cells. No viral particles were seen.
\end{abstract}

Six extraskeletal giant cell tumors have been reported in cats $[4,6,8]$. The name malignant fibrous histiocytoma has been suggested because these tumors in cats histologically resemble neoplasms of that name in man $[6,12]$. These neoplasms arise in subcutaneous tissues and the deep dermis. Characteristically, they grow rapidly and reach a large size. Local invasion and recurrence after excision are common. There have been no reports of metastasis.

Histologically, these tumors are composed of bundles of spindle to polyhedral cells that may form a whorled pattern $[3,6,8]$. Scattered throughout the lesions are numerous multinucleated giant cells of neither skeletal-muscle nor osteoclast origin. The ultrastructure of one of these tumors was described briefly [4].

We describe the ultrastructural appearance of an extraskeletal giant-cell tumor in a cat.

\section{Case History}

A 9-year-old neutered male Domestic Shorthair cat was presented with a freely movable subcutaneous mass $2 \mathrm{~cm}$ in diameter along the dorsal thoracic midline between the blades of the scapulae. The mass did not involve underlying muscle and was removed surgically. During the next 15 -month period the mass recurred six times 
and on each occasion was removed. Tumor invasion of subcutaneous muscle was seen at the fourth surgical intervention and each time thereafter. There was no metastasis.

\section{Materials and Methods}

Tissue for light microscopy was collected at surgery and fixed in $12 \%$ neutral buffered formalin, processed in an automatic tissue processor, embedded in paraffin, cut in $6-\mu \mathrm{m}$ sections, and stained with hematoxylin and eosin (HE). Special stains included Mallory's phosphotungstic acid-hematoxylin and Masson's trichrome [7].

Tissue for electron microscopy was taken at the third surgical removal of the mass. The tissue was minced and fixed immediately in cold $2.5 \%$ glutaraldehyde for four hours, then post-fixed in $1 \%$ osmium tetroxide, dehydrated in a series of graded alcohols, and embedded in a polyester resin. Semi-thin sections $(0.5 \mu \mathrm{m})$ were stained with toluidine blue and ultrathin sections with uranyl acetate and lead citrate.

Blood smears from the cat were negative for feline leukemia virus by indirect immunofluorescence.

\section{Results}

The excised masses were firm, of various shapes, and 1 to $8 \mathrm{~cm}$ in diameter. The cut surfaces were pale yellow-gray with multifocal areas of liquefactive necrosis.

Histologically, the neoplasm was similar at each sampling and resembled those described previously $[3,4,6,8]$. The mass was partially circumscribed by a thin fibrous connective-tissue capsule and was composed of large interlacing bundles of pleomorphic spindle to polyhedral cells in a dense to moderately vacuolated fibrous connective-tissue stroma (fig. 1). Scattered randomly throughout the mass were many large, irregularly shaped multinucleated giant cells. Phosphotungstic acid-hematoxylin stains showed no striations in the cytoplasm. There was less than one mitotic figure per high power field. In specimens taken at later surgeries, tumor foci had infiltrated adjacent skeletal muscle bundles.

Ultrastructurally, the mass was composed of several cell types. The most prominent were fibroblast-like cells, histiocyte-like cells and giant cells. Less common were undifferentiated cells and mononuclear cells intermediate between fibroblasts and histiocytes. No viral particles were seen.

The fibroblast-like cells were elongated or polygonal with a slightly undulating to smooth cytoplasmic membrane, and often were closely associated with collagen fibers (fig. 2, 3). A few villous membrane projections were seen. The cytoplasm contained many mitochondria. Rough endoplasmic reticulum was abundant and often dilated with granular material. Moderate numbers of polyribosomes were scattered randomly throughout the cytoplasm. The Golgi apparatus was well developed. There were a few small membrane-bound, electron-dense structures, probably primary lysosomes. Occasionally, a residual body was seen. The nuclei were usually oval. The chromatin was finely granular and usually distributed evenly throughout the nuclei, although heterochromatin was seen occasionally. When present, nucleoli were of various sizes and either dense or reticular. 


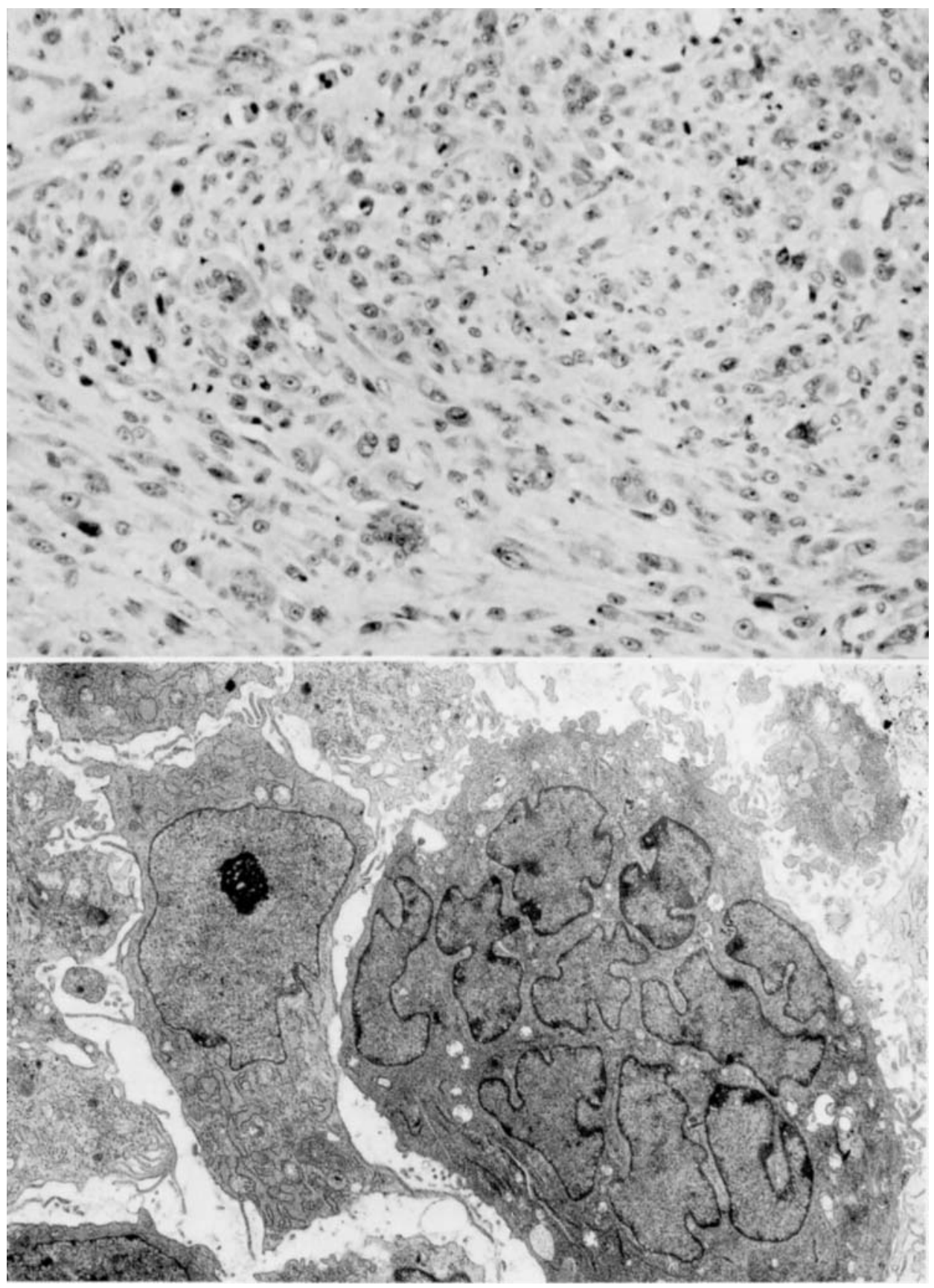

Fig. 1: Histologic appearance of extraskeletal giant cell tumor: giant cells and spindle to polygonal cells. HE.

Fig. 2: Fibroblast-like cell adjacent to multinucleated giant cell. 


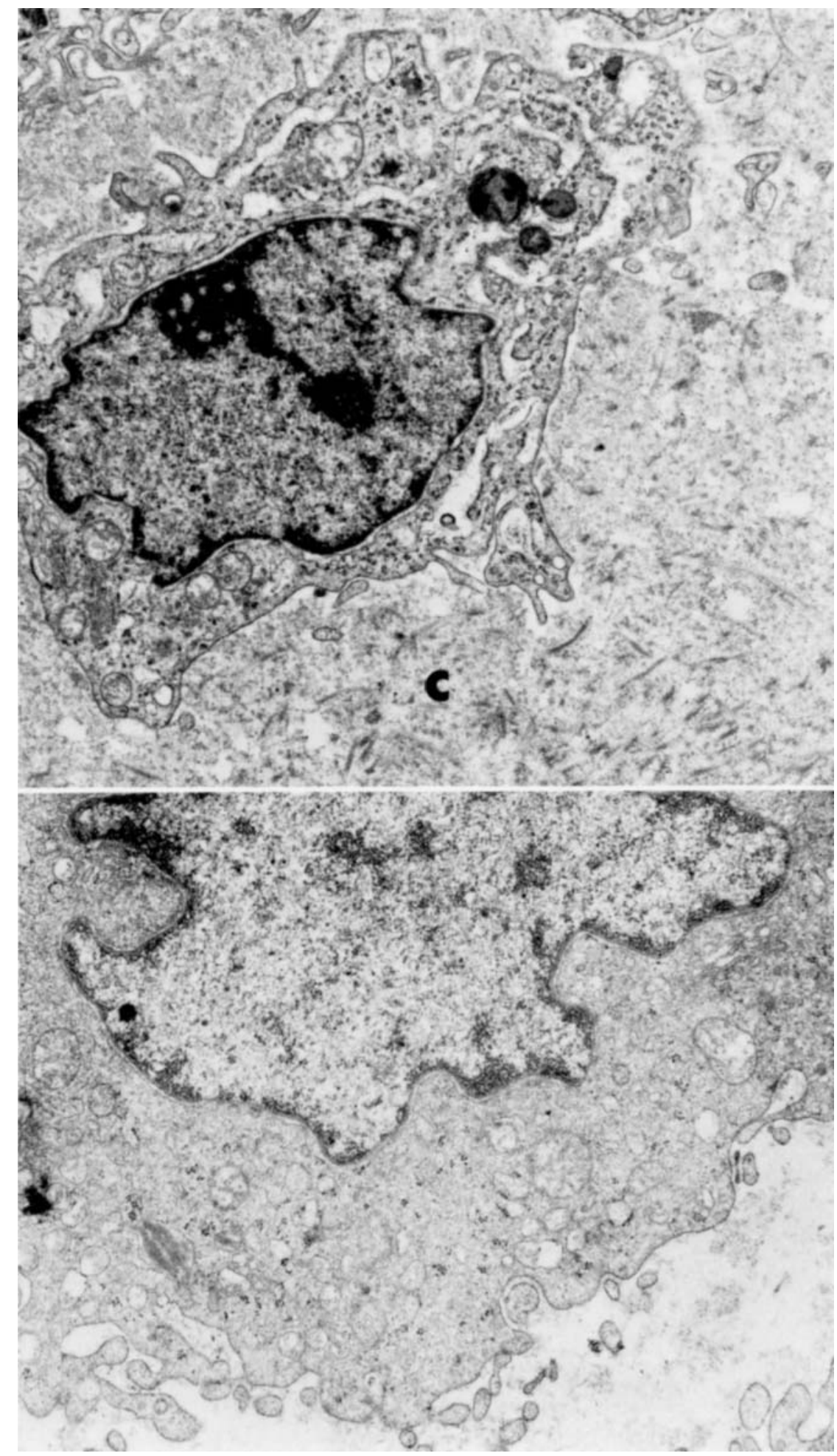

Fig. 3: Fibroblast-like cell in dense collagen matrix (C). Well-developed rough endoplasmic reticulum, relatively smooth cell membranes.

Fig. 4: Histiocyte-like cell with scant rough endoplasmic reticulum. 


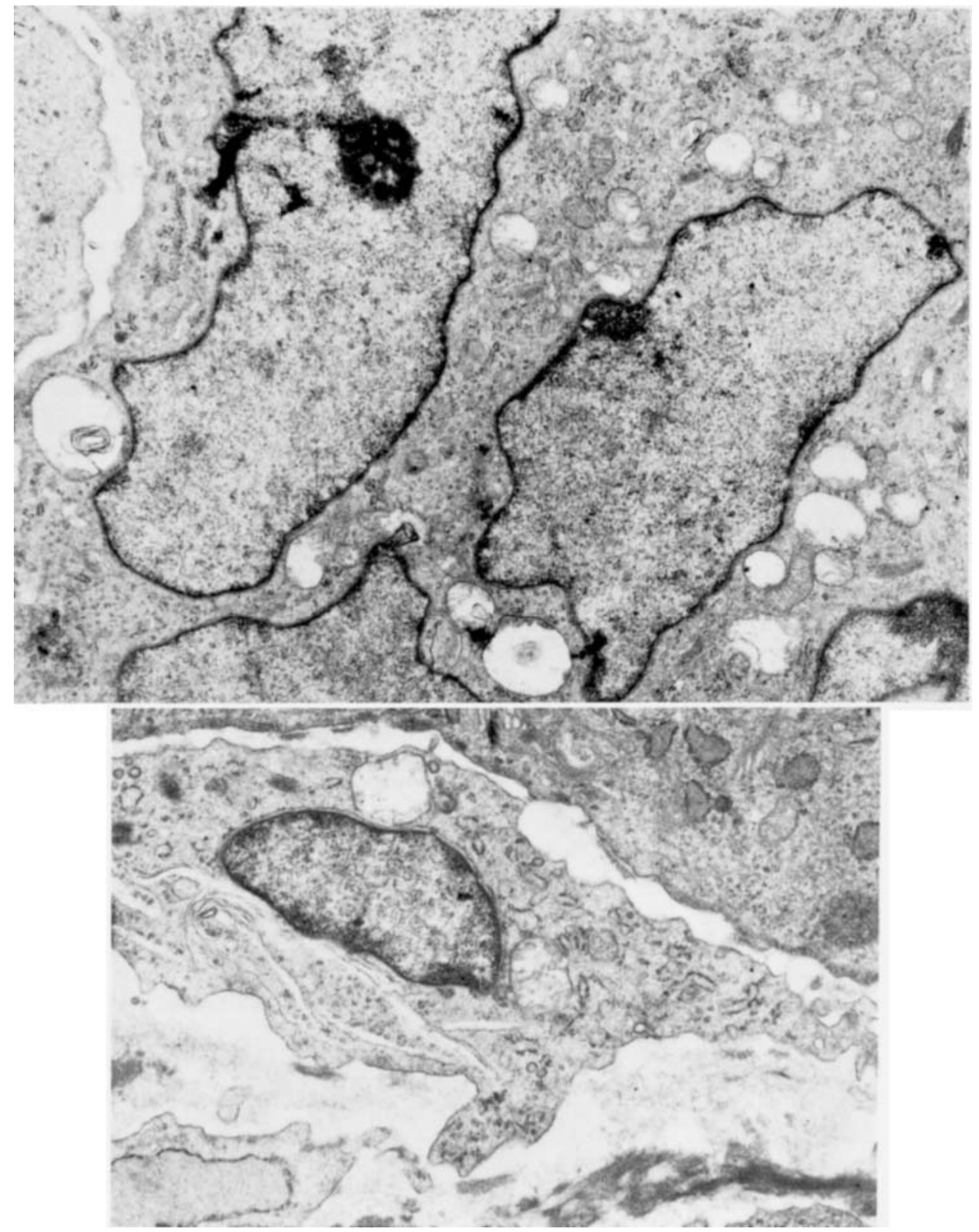

Fig. 5: Multinucleated giant cell with numerous cytoplasmic vacuoles occasionally containing myelin figures.

Fig. 6: Undifferentiated cell with few cytoplasmic organelles.

The histiocyte-like cells resembled immature macrophages [1], were round to polygonal, and were more varied than the fibroblast-like cells. The cell membranes formed numerous elongated irregular villous processes that interdigitated with processes from adjacent cells (fig. 4). Mitochondria were numerous. Rough endoplasmic 
reticulum varied from scant to moderate and seldom was dilated. Free polyribosomes usually were numerous. Small lamellar arrays of smooth endoplasmic reticulum were present occasionally, although no well-developed Golgi apparatus were seen. Numerous small lysosomal or phagocytic bodies in the cytoplasm looked like single membrane-bound vesicles that occasionally were electron-dense but most often contained granular material or myelin figures. Nuclei were oval to convoluted; an occasional binucleate cell was seen. The chromatin was finely to coarsely granular, occasionally clumped and marginated. The nucleoli usually were dense.

The giant cells had characteristics of both the fibroblast-like and histiocyte-like cells. Typically, mitochondria were numerous. Rough endoplasmic reticulum varied from abundant to scant (fig. 2, 5). Like the histiocyte-like cells, the cytoplasmic membranes usually formed numerous villous processes. Lysosomal structures varied in number, and typically were small and granular. Dilated vesicles with myelin figures also were seen. The chromatin was either finely or coarsely granular with foci of heterochromatin. Nucleoli varied from dense and compact to loosely arranged and granular, and showed some disintegration.

On occasion, undifferentiated cells were seen. They had various shapes and smooth membranes. The cytoplasm contained few organelles, and thus looked electronlucent (fig. 6).

\section{Discussion}

Histologically, this tumor resembled those previously described as feline extraskeletal giant-cell tumors or malignant fibrous histiocytomas $[3,4,6,8]$. Also, it had ultrastructural characteristics similar to those described in malignant fibrous histiocytomas in man $[2,5]$. The tumor was composed primarily of fibroblast-like and histiocyte-like cells as well as giant cells with characteristics of both cell types. There were fewer undifferentiated cells and mononuclear cells that could not be classified as either fibroblast-like or histiocyte-like. Myofibroblast-like cells have been recognized in some malignant fibrous histiocytomas in man $[2,5]$. No bundles of contractile filaments were seen, however, in the fibroblast-like cells in this tumor.

The histogenesis of the malignant fibrous histiocytoma has been controversial. Originally it was thought that the tissue histiocyte was the cell of origin and that certain cells acted as "facultative-fibroblasts" [9]. The most recent ultrastructural studies have shown undifferentiated cells and cells intermediate between fibroblasts and histiocytes in the neoplasms [2,5]. These findings have been the basis for the current theory that the cell of origin is a pluripotential undifferentiated mesenchymal cell that gives rise to histiocyte-like, fibroblast-like and intermediate cells [12]. Studies of the pluripotential nature of primitive mesenchymal cells in developing bone seem to support this concept [10].

The ultrastructural pleomorphism of feline mesenchymal tumors is not specific for the malignant fibrous histiocytoma. Transmissible feline fibrosarcomas differ histologically and behaviorally from the tumor described in this and previous reports [11]. Also, no viral particles were seen in our tumor. In experimentally induced feline fibrosarcomas, however, three cell types were described ultrastructurally [11]. Most 
prominent were fibroblast-like cells. Also present were cells described as resembling macrophages as well as some that were intermediate in structure between fibroblasts and macrophages. It was the authors' opinion that these cell types were different stages of differentiation of the same stem cell.

Based on light- and electron-microscopic findings, the extraskeletal giant cell tumor of cats is strikingly similar to malignant fibrous histiocytoma in man. Additional ultrastructural studies of these tumors in cats are needed to confirm that they are a true counterpart of this group of tumors in man.

\section{Acknowledgements}

The authors wish to thank Diane Weigand and Judy Donovan for excellent technical assistance.

\section{References}

1 ADAms, D.O.: The structure of mononuclear phagocytes differentiating in vivo. I. Sequential fine and histologic studies of the effect of Bacillus Calmette-Guerin (BCG). Am J Pathol 76:17-48, 1974

2 Alequacil-Garcia, A.; UNNI, K.K.; Goellner, J.R.: Malignant fibrous histiocytoma: An ultrastructural study of six cases. Am J Clin Pathol 69:121-129, 1978

3 Alexander, J.W.; Rirs, R.C.; Dueland, R.: Extraskeletal giant cell tumor in a cat. Vet Med 70:1161-1166, 1975

4 Ford, G.H.; Empson, R.N.; Plopper, C.G.; Brown, P.H.: Giant cell tumor of soft parts. A report of an equine and a feline case. Vet Pathol 12:428-433, 1975

5 FU, Y.S.; GabbianI, G.; KaY, G.I.; Latres, R.: Malignant soft tissue tumors of probable histiocytic origin (malignant fibrous histiocytomas): General considerations and electron microscopic and tissue culture studies. Cancer 35:176-198, 1975

6 Gleiser, C.A.; Raulston, G.L.; Jardine, J.H.; Gray, K.N.: Malignant fibrous histiocytoma in dogs and cats. Vet Pathol 16: 199-208, 1979

7 Luna, L.G.: Manual of Histologic Staining Methods of the Armed Forces Institute of Pathology, 3rd ed., pp. 85-86, 94-95. McGraw-Hill, New York, 1968

8 Nielsen, S.W.: Extraskeletal giant cell tumor in a cat. Cornell Vet 42:304-311, 1952

9 Ozzello, L.; Stout, A.P.; MurRay, M.R.: Cultural characteristics of malignant histiocytomas and fibrous xanthomas. Cancer 16:331-344, 1963

10 ScotT, B.L.: Thymidine- ${ }^{3} \mathrm{H}$ electron microscopic radioautography of osteogenic cells in the fetal rat. J Cell Biol 35:115-126, 1967

11 Snyder, S.P.; Theilen, G.H.; Richards, W.P.C.: Morphological studies on transmissible feline fibrosarcoma. Cancer Res 30: 1658-1667, 1970

12 Weiss, S.W.; EnZINGeR, F.M.: Malignant fibrous histiocytoma: An analysis of 200 cases. Cancer 41:2250-2266, 1978

Request reprints from A. W. Confer, Department of Veterinary Pathology, School of Veterinary Medicine, Louisiana State University, Baton Rouge, LA 70803 (USA). 